\title{
High mass-specific reactivity of a defect-enriched Ru electrocatalyst for hydrogen evolution in harsh alkaline and acidic media
}

\author{
Yuanli $\mathrm{Li}^{1,2}$, Jingfu $\mathrm{He}^{3^{*}}$, Weiren Cheng ${ }^{1}$, Hui Su${ }^{1}$, Changli $\mathrm{Li}^{3}$, Hui Zhang ${ }^{1}$, Meihuan Liu ${ }^{1}$, \\ Wanlin Zhou ${ }^{1}$ Xin Chen ${ }^{4 *}$ and Qinghua Liu ${ }^{1 *}$
}

\begin{abstract}
A reasonable design strategy to improve the utilization of noble metal electrocatalysts for the hydrogen evolution reaction (HER) is crucial to simplify the process flow and accelerate the future renewable energy economy. Here, abundant defects were created on 2.4-nm Ru nanoparticles to achieve unprecedently high mass-specific reactivity in harsh acidic and alkaline electrolytes. The obtained defect-enriched Ru (DR-Ru) exhibits an ultrahigh HER turnover frequency of $16.4 \mathrm{~s}^{-1}$ with a $100-\mathrm{mV}$ overpotential in alkaline media, and it also retains an excellent value of $20.6 \mathrm{~s}^{-1}$ in acidic media; these results are superior to those reported for other $\mathrm{Ru}$ catalysts. Accordingly, a record-low loading of $2.5 \mu \mathrm{g} \mathrm{cm}^{-2}$ for the DR$\mathrm{Ru}$ catalysts and low overpotentials of 28.2 and $25.1 \mathrm{mV}$ at $10 \mathrm{~mA} \mathrm{~cm}{ }^{-2}$ can be realized in alkaline and acidic media, respectively. Furthermore, the less coordinated Ru surface sites and partial lattice oxygen introduction weaken the bonding between $H$ and DR-Ru catalysts, facilitate fast acidic HER kinetics and help dissociate the water molecule to overcome the major challenge of HER in alkaline electrolytes, leading to an activity comparable to that under acidic conditions. This result provides a guideline for defect engineering on noble metal nanocatalysts to effectively improve the utilization of the catalysts and optimize reactivities.
\end{abstract}

Keywords: defect engineering, DR-Ru catalyst, hydrogen evolution reaction, electrocatalysis

\section{INTRODUCTION}

Efficient electrocatalysts for hydrogen production are at the core of the modern renewable energy economy based on hydrogen energy, which requires a deep understanding and ongoing simplification in the design of novel catalysts. Platinum-group metal electrocatalysts, such as those with $\mathrm{Pt}, \mathrm{Ru}$ and $\mathrm{Ir}$, have superior hydrogen evolution reaction (HER) intrinsic reactivities compared with those of other mature or emerging catalysts, such as NiMo or Raney nickel, and are currently the most common commercial HER catalysts [1-5]. However, the scarcity and high cost of platinum-group metal electrocatalysts and their nonuniform performance in acidic and alkaline electrolytes still represent critical bottlenecks that limit the large-scale practical application of electrolytic $\mathrm{H}_{2}$ production [6,7]. The widely accepted solution is to maximize the mass-specific reactivity and reduce the loading of the precious metals. Theoretically, single-atom catalysts could maximize the utilization of noble metals [8]. Yao's group [9] reported a single-atom $\mathrm{Pt}_{1} / \mathrm{N}-\mathrm{C}$ HER catalyst that can realize a current density of $10 \mathrm{~mA} \mathrm{~cm}^{-2}$ with application of a $19-\mathrm{mV}$ overpotential in $0.5 \mathrm{~mol} \mathrm{~L}^{-1}$ $\mathrm{H}_{2} \mathrm{SO}_{4}$ and a $46-\mathrm{mV}$ overpotential in $1.0 \mathrm{~mol} \mathrm{~L}^{-1} \mathrm{NaOH}$. Song's group [10] synthesized dispersed $\mathrm{Pt}$ on onion-like nanospheres of carbon $(0.27 \mathrm{wt} \% \mathrm{Pt})$ that can reach $10 \mathrm{~mA} \mathrm{~cm}^{-2}$ at a $38-\mathrm{mV}$ overpotential. However, under actual reaction conditions, it is difficult to synthesize single-atom catalysts, which have high fluidity and are

\footnotetext{
${ }^{1}$ National Synchrotron Radiation Laboratory, University of Science and Technology of China, Hefei 230029, China

${ }^{2}$ Fundamental Science on Nuclear Wastes and Environmental Safety Laboratory, Southwest University of Science and Technology, Mianyang 621010, China

${ }^{3}$ School of Materials, Sun Yat-sen University, Guangzhou 510275, China

${ }^{4}$ Center for Computational Chemistry and Molecular Simulation, College of Chemistry and Chemical Engineering, Southwest Petroleum University, Chengdu 610500, China

* Corresponding authors (emails: hejf27@mail.sysu.edu.cn (He J); chenxin830107@pku.edu.cn (Chen X); qhliu@ustc.edu.cn (Liu Q))
} 
easily sintered [11]. Moreover, the activities of Pt-based catalysts under alkaline conditions are obviously lower than those under acidic conditions. Hence, developing a facile strategy to maximize the mass-specific reactivity of platinum-group metal electrocatalysts is highly desirable.

Although single-atom catalysts can, theoretically, fully utilize the loading of the noble metal, nanoparticles (NPs) of 2-3 nm diameter would have $50 \%$ of the atoms on the surface and are much easier to synthesize. Catalyst design based on small NPs is a promising alternative strategy for realizing the effective utilization of noble metal catalysts. "Defect engineering" is an exciting concept for tuning material properties, which opens novel channels in material chemistry for mechanical, electronic and catalytic applications [12-18]. Defect tailoring of electrochemical catalysts is particularly interesting because the defects in catalysts can change the distribution of electronic charge and control the disordered structure, and it plays a crucial role in manipulating the structures of intermediates in electrocatalytic reactions $[19,20]$. Numerous attempts have been made to control the defect types, structures and concentrations of catalysts, which can be generally divided into synthetic and post-synthetic methods. For instance, rich-edge defects have been regulated by the optimization of pyrolysis temperatures and mass ratios of precursors $[21,22]$. By constructing hBN heterostructure layers on $\mathrm{N}$-doped carbon nanostructures, more defects can be exposed to boost the HER electrocatalytic activity [23]. Compared with the synthetic methods, post-synthetic methods are more feasible for intentionally inducing controllable defects. Cai's group [24] selectively etched $\mathrm{WO}_{3}$ contaminants by alkali etching post-treatment to obtain highly defective $\mathrm{WS}_{2}$ nanosheets for efficient HER catalysis. Different types of defects can be created on $\mathrm{MoS}_{2}$ monolayers by applying different posttreatments; e.g., a great number of cracks with certain angles were created by oxygen plasma treatment and various micrometer- and nanometer-scale triangular holes resulted from hydrogen annealing [25]. However, most defect engineering studies are carried out on at least a one-dimensional micron-scale material matrix. There remains a strikingly small body of experimental data for successfully manipulating defects in nanometer materials.

Herein, we used $\mathrm{Ru}$, the cheapest Pt group element, in a proof-of-concept study [26] and successfully constructed defects with a uniform size of $\sim 2.4 \mathrm{~nm}$ in defect-enriched $\mathrm{Ru}$ NPs (DR-Ru NPs) by a two-step synthetic strategy. The synthesis of DR-Ru NPs profits from the coexistence of $\mathrm{Cu}$ in the precursor $\mathrm{RuCu}$ nanocrystals, which can be facilely etched away to create defects. The mass-specific reactivity of $\mathrm{DR}-\mathrm{Ru}$ is superior to that of any other $\mathrm{Ru}$ HER catalyst reported, with an ultrahigh turnover frequency (TOF) of $16.4 \mathrm{~s}^{-1}$ in alkaline media and $20.6 \mathrm{~s}^{-1}$ in acidic solution at an overpotential of $100 \mathrm{mV}$. X-ray absorption near edge structure (XANES), extended X-ray absorption fine structure (EXAFS) and X-ray photoelectron spectroscopy (XPS) analyses disclose that the enriched defects in the DR-Ru introduce lattice Os into the subsurface of the $\mathrm{Ru}$ and greatly lower the coordination number $(\mathrm{CN})$ of the surface $\mathrm{Ru}$ atoms, leading to the overall optimization of the electronic structure and coordination environment of the active sites. This optimized Ru surface model can weaken the bonding strength of the catalyst and $\mathrm{H}$ and accelerate water molecule dissociation, contributing to excellent HER activities.

\section{EXPERIMENTAL SECTION}

\section{Synthesis of Ru-based NPs}

Typically, DR-Ru catalysts were first prepared by the galvanic replacement method with the adjusted reaction time of $5 \mathrm{~h}$ [27]. Then, the washed products were dispersed in an appropriate amount of cyclohexane, sprayed onto a clean carbon cloth (CC) with an area of $1 \mathrm{~cm}^{2}$ and heated to $450^{\circ} \mathrm{C}$ for $2 \mathrm{~h}$ in a $\mathrm{H}_{2} / \mathrm{Ar}$ atmosphere. Subsequently, the resulting sample was soaked in $\mathrm{FeCl}_{3}$ solution overnight and washed with deionized water. And then, the precipitated $\mathrm{Cu}$ was etched out, and DR-Ru NPs loaded on CC could be obtained after vacuum drying. As a reference sample, normal Ru NPs loaded on CC were also synthesized according to the same procedure without a $\mathrm{Cu}$-containing precursor or $\mathrm{FeCl}_{3}$ etching.

\section{Characterizations}

We performed transmission electron microscopy (TEM) and high-resolution TEM (HRTEM) on a JEOL JEM2100F microscope to obtain the morphologies of the catalysts. We also obtained crystal structure information with X-ray diffraction (XRD) on a PANalytical X'Pert PRO XRD diffractometer $(\mathrm{Cu} \mathrm{Ka}$ radiation, $\lambda=$ $1.54178 \AA$ ), and the detection range was $2 \theta=10^{\circ}-70^{\circ}$. The oxidation state and electronic structural changes were further acquired by X-ray photoelectron spectroscopy (XPS) on an ESCALAB MKII instrument (excitation source: $\mathrm{Mg} \mathrm{Ka}, h v=1253.6 \mathrm{eV}$ ). All obtained XPS results were corrected by referencing $\mathrm{C} 1 \mathrm{~s}$ to $284.8 \mathrm{eV}$. Aberration-corrected high-angle annular dark-field scanning TEM (HAADF-STEM) was conducted to discern the $\mathrm{Ru}$ vacancies and other defect species on a JEMARM 200F instrument at an accelerating voltage of 
$200 \mathrm{kV}$. We conducted operando synchrotron radiation Fourier transform infrared (SR-FTIR) measurements at the infrared beamline BL01B of the National Synchrotron Radiation Laboratory (NSRL, China), and a homemade top-plate cell was used to perform the electrochemical tests. The spectral resolution was set as $2 \mathrm{~cm}^{-1}$ to ensure the quality of the obtained SR-FTIR spectra, and before data collection, a voltage was applied to the catalyst electrode for $20 \mathrm{~min}$ to obtain a stable and reliable signal. We carried out the electrochemical tests on a standard three-electrode electrochemical workstation (CHI760E). For alkaline electrolysis, the electrodes were immersed in a $\mathrm{KOH}$ solution $\left(1 \mathrm{~mol} \mathrm{~L}^{-1}\right)$ with a $\mathrm{Pt}$ wire and $\mathrm{Hg} / \mathrm{HgO}$ (saturated $\mathrm{KOH}$ ) as the counter and reference electrodes. The acidic electrolysis was done in a $0.5 \mathrm{~mol} \mathrm{~L}^{-1} \mathrm{H}_{2} \mathrm{SO}_{4}$ solution, and graphite and $\mathrm{Ag} / \mathrm{AgCl}$ (saturated $\mathrm{KCl}$ ) acted as the counter and reference electrodes, respectively. We first performed dozens of CV scans to stabilize the sample and then obtained linear sweep voltammetry (LSV) curves by measuring at a scanning rate of $10 \mathrm{mV} \mathrm{s}^{-1}$ with an $80 \% I R$ correction. The stability measurement was conducted at an initial current density of $10 \mathrm{~mA} \mathrm{~cm}^{-2}$ for $20 \mathrm{~h}$ with the amperometric current-time $(i-t)$ curve pattern.

\section{RESULTS AND DISCUSSION}

The synthesis of DR-Ru NPs was realized by a two-step strategy that benefited from the incompatibility of Ru and $\mathrm{Cu}$ during crystallization [28]. First, $\mathrm{Ru}$ and $\mathrm{Cu}$ precursors were mixed together for a solvothermal reaction that produced incipient coexisting $\mathrm{RuCu}$ nanocrystals (pre- $\mathrm{RuCu}$ ). $\mathrm{Cu}$ seeds were preferentially formed at the beginning of the solvothermal reaction and $\mathrm{Ru}$ epitaxial shells consequentially wrapped the $\mathrm{Cu}$ core to achieve a thermodynamically stable structure [27]. Proper annealing of pre- $\mathrm{RuCu}$ in a reducing atmosphere precipitated the $\mathrm{Cu}$ core to reconstruct the pre- $\mathrm{RuCu}$, which was then etched by $\mathrm{FeCl}_{3}$ solution, leaving $\mathrm{Ru}$ with enriched defects. As a reference, Ru NPs were synthesized by the same procedure without a $\mathrm{Cu}$ precursor. The morphologies of the $\mathrm{Ru}$ and $\mathrm{DR}-\mathrm{Ru}$ catalysts were determined by TEM, and the images are shown in Fig. 1a, c. The Ru NPs exhibit a spherical morphology with an average size of $\sim 3.3 \mathrm{~nm}$. Cu treatment can further reduce the nanoparticle size, resulting in DR-Ru catalysts with an anomalous near-spherical morphology and a uniform
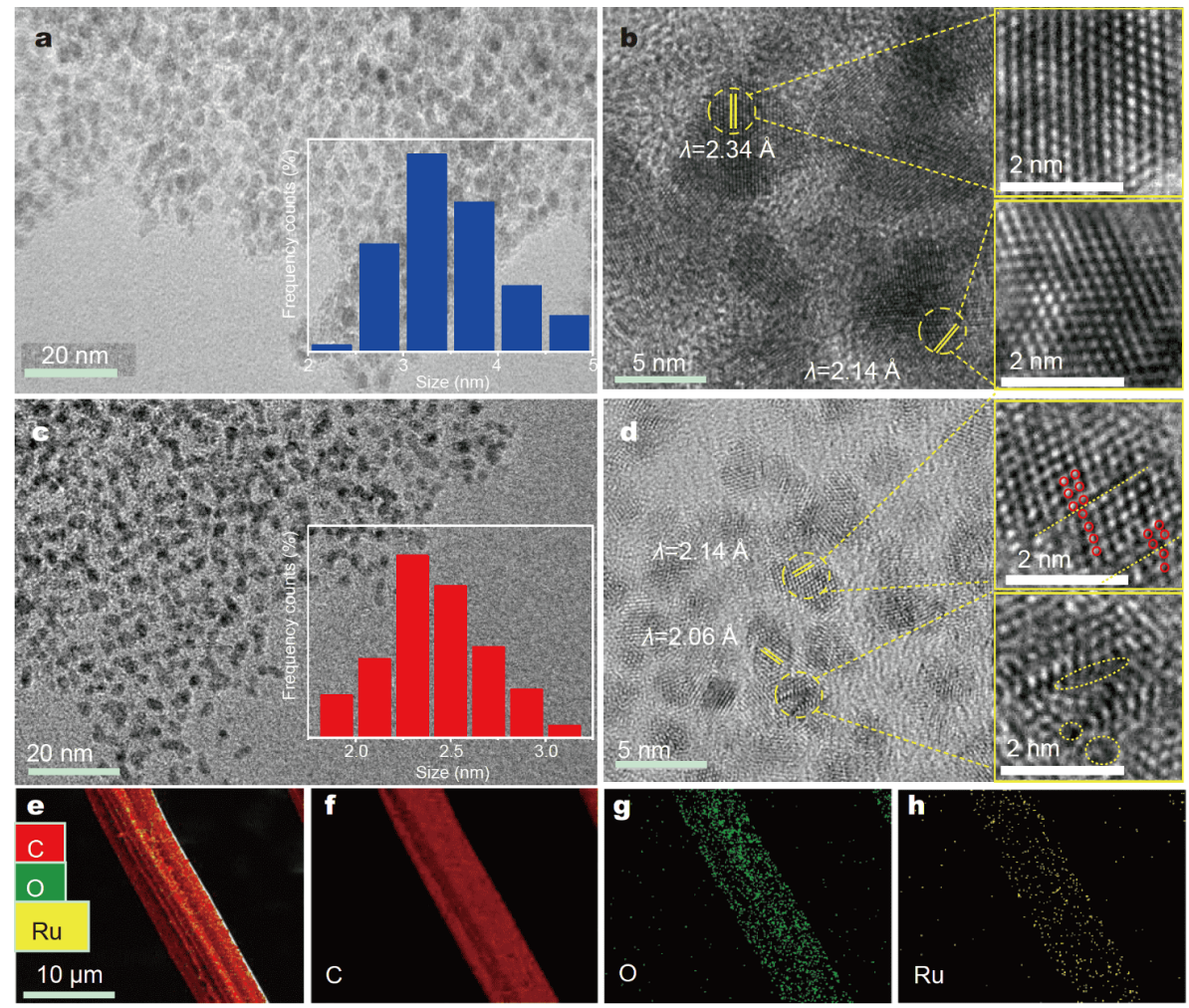

Figure 1 TEM and HRTEM images of the as-prepared $\mathrm{Ru}(\mathrm{a}, \mathrm{b})$ and DR-Ru $(\mathrm{c}, \mathrm{d})$. The insets in $(\mathrm{b}, \mathrm{d})$ are local enlarged versions. (e-h) EDS mappings of total, $\mathrm{C}, \mathrm{O}$, and $\mathrm{Ru}$ in DR-Ru. 
average size of $\sim 2.4 \mathrm{~nm}$. There was no recognizable $\mathrm{Cu}$ signal in the inductively coupled plasma (ICP) emission spectrometry test of the DR-Ru sample or energy dispersive X-ray spectroscopy (EDS) results (Fig. S1) after $\mathrm{FeCl}_{3}$ etching, indicating that $\mathrm{Cu}$ was completely etched away. The interplanar spacings of $\mathrm{Ru}$ and DR-Ru NPs, obtained from HRTEM images (Fig. 1b, d), are approximately $2.34,2.14$ or $2.06 \AA$, corresponding to the (100), (002), and (101) lattice planes, respectively, of the typical hexagonal close-packed ( $h c p$ ) structure of Ru. Ru NPs have ordered lattice fringes shown in the inset of Fig. 1b, suggesting excellent crystallinity. However, the lattice fringes of DR-Ru NPs are partially disordered. As shown in the inset of Fig. 1d, there is an obvious dislocation of lattice fringes marked by the yellow dotted line and even vacancies marked by the yellow circle in the DR-Ru sample, proving the increased number of defects in the DR-Ru after $\mathrm{Cu}$ etching. The HAADF-STEM image of DR-Ru further demonstrates the existence of abundant defects (Fig. S2).

To achieve a DR-Ru-loaded CC electrode, a pre- $\mathrm{RuCu}$ NP solution was first sprayed onto CC and then treated with the same process. The corresponding $\mathrm{Ru}$ loading mass revealed by ICP-mass spectrometry (MS) measurement is approximately $2.462 \mu \mathrm{g} \mathrm{cm}^{-2}$, suggesting that this strategy is quite convenient for obtaining Ru-based catalysts with extremely low loadings. Due to the low loading mass and the ultrafine size, no other characteristic peaks were observed by XRD except for those of the CC, as shown in Fig. S3 [29]. To further examine the crystal structure, we increased the loading and repeated the XRD measurement. The XRD peaks of DR-Ru were well matched with those for the typical $h c p$ Ru structure (PDF\#657646), consistent with the TEM analysis (Fig. S4). The EDS mappings of DR-Ru shown in Fig. 1e-h display the uniform distribution of $\mathrm{Ru}$ on the CC.

The HER electrocatalytic activity and stability of the DR-Ru catalysts were evaluated through a typical threeelectrode setup in $0.5 \mathrm{~mol} \mathrm{~L}^{-1} \mathrm{H}_{2} \mathrm{SO}_{4}$ or $1 \mathrm{~mol} \mathrm{~L}^{-1} \mathrm{KOH}$ solution. Under acidic conditions, the overpotential for $\mathrm{DR}-\mathrm{Ru}$ catalysts to drive a $10 \mathrm{~mA} \mathrm{~cm}^{-2}$ catalytic current density was $25.1 \mathrm{mV}$, superior to commercial $\mathrm{Pt} / \mathrm{C}$ $(34.7 \mathrm{mV})$ and just about one-third of that of Ru NPs (73.2 mV). Furthermore, the Tafel slope for DR-Ru catalysts in $0.5 \mathrm{~mol} \mathrm{~L}^{-1} \mathrm{H}_{2} \mathrm{SO}_{4}$ was close to the theoretically predicted value for the Volmer-Tafel mechanism $\left(\sim 30 \mathrm{mV} \mathrm{dec}^{-1}\right)$, with a Tafel slope of $23.8 \mathrm{mV} \mathrm{dec}^{-1}$, implying that its fast dynamics is similar to that of the benchmark electrode with commercial $\mathrm{Pt} / \mathrm{C}$ $\left(23.6 \mathrm{mV} \mathrm{dec}{ }^{-1}\right)$. In contrast, the Tafel plot for Ru NPs without $\mathrm{Cu}$ treatment showed a Tafel slope of $54.8 \mathrm{mV} \mathrm{dec}^{-1}$. Interestingly, the DR-Ru catalysts showed comparable HER activity in the alkaline electrolyte with $1 \mathrm{~mol} \mathrm{~L}^{-1} \mathrm{KOH}$. It is well known that noble metal catalysts show inferior HER activities in alkaline electrolytes compared with acidic electrolytes [26,30,31], which is mainly caused by the extra energy required for the additional water dissociation step. This phenomenon was also evident in our HER experiments with $\mathrm{Pt} / \mathrm{C}$ and $\mathrm{Ru}$ catalysts in $1 \mathrm{~mol} \mathrm{~L}^{-1} \mathrm{KOH}$, which exhibited overpotentials of 61.2 and $14 \mathrm{mV}$ larger than those with $0.5 \mathrm{~mol} \mathrm{~L}^{-1} \mathrm{H}_{2} \mathrm{SO}_{4}$. However, as shown in Fig. 2a, DR-Ru catalysts rapidly reached a current density of $10 \mathrm{~mA} \mathrm{~cm}^{-2}$ at a low overpotential of $28.2 \mathrm{mV}$ in $1 \mathrm{~mol} \mathrm{~L}^{-1} \mathrm{KOH}$ solution, which is much better than those of commercial $\mathrm{Pt} /$ $\mathrm{C}(95.9 \mathrm{mV})$ and Ru NPs $(87.2 \mathrm{mV})$. The corresponding Tafel slopes were calculated to illustrate the reaction kinetics, as shown in Fig. 2b, and were found to be $40.8 \mathrm{mV} \mathrm{dec}^{-1}$ for DR-Ru catalysts, $42.9 \mathrm{mV} \mathrm{dec}^{-1}$ for commercial $\mathrm{Pt} / \mathrm{C}$ and $69.0 \mathrm{mV} \mathrm{dec}^{-1}$ for $\mathrm{Ru} \mathrm{NPs}$ in $1 \mathrm{~mol} \mathrm{~L}^{-1} \mathrm{KOH}$. This shows that the DR-Ru catalysts exhibit faster reaction kinetics than $\mathrm{Ru}$ catalysts and proceed via successive Volmer-Heyrovsky paths in the basic solution [32]. Additionally, the durability of DR-Ru catalysts was further examined by chronoamperometric measurements, and the results are shown in Fig. 2c. DR$\mathrm{Ru}$ catalysts remained relatively stable over $20 \mathrm{~h}$ of operation at a $28-\mathrm{mV}$ overpotential in basic solution. However, under acidic conditions, the stability of DR-Ru was slightly reduced at $25 \mathrm{mV}$, and the initial current density was reduced to approximately $9 \mathrm{~mA} \mathrm{~cm}^{-2}$, ascribed to the dissolution of some surface-oxidized $\mathrm{Ru}$ in acidic solution $[26,33]$. In addition, the almost unchanged structure and electrochemical behavior shown in Fig. S5 evidently confirmed the robust long-term durability of DR-Ru while operating in HER catalysis.

For noble metal electrocatalysts, mass-specific reactivity determines the amount of catalyst used in a water-splitting reactor, which is crucial to the cost of scale-up applications. The TOF can be explicitly calculated to characterize the intrinsic electrocatalytic activity per atom. Because of the high surface area of small NPs and the surface defect engineering, the loading amount of DR$\mathrm{Ru}$ in our experiment was greatly reduced to $<2.5 \mu \mathrm{g} \mathrm{cm}^{-2}$, which is the lowest reported for $\mathrm{Ru}$ catalysts. DR-Ru displays a high TOF value of $\sim 20.6 \mathrm{~s}^{-1}$ in $0.5 \mathrm{~mol} \mathrm{~L}^{-1} \mathrm{H}_{2} \mathrm{SO}_{4}$. Although this value is not as large as those reported for Pt-based electrocatalysts $\left(40.8 \mathrm{~s}^{-1}\right.$ for $\mathrm{Pt}_{1} / \mathrm{OLC}$ ) [10], it is still 5 times higher than those of other $\mathrm{Ru}$ catalysts $\left(3.9 \mathrm{~s}^{-1}\right)$. This TOF value was greater than 

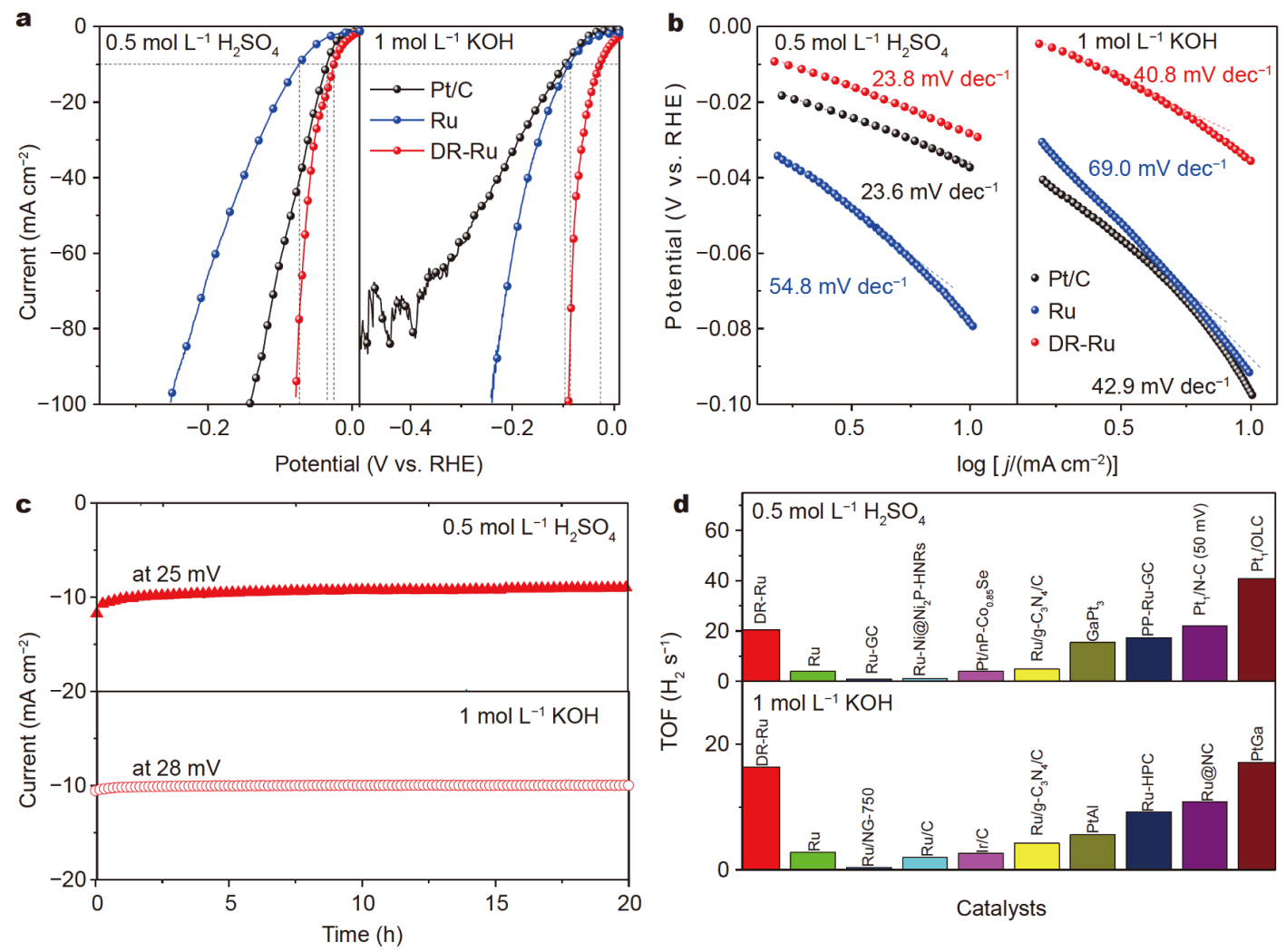

Figure 2 Electrochemical measurements in $0.5 \mathrm{~mol} \mathrm{~L}^{-1} \mathrm{H}_{2} \mathrm{SO}_{4}$ or $1 \mathrm{~mol} \mathrm{~L}^{-1} \mathrm{KOH}$ solution. (a) Polarization curves of Pt/C, $\mathrm{Ru}$ and $\mathrm{DR}-\mathrm{Ru}$ catalysts. (b) Tafel plots obtained from the polarization curves in (a). (c) Stability test of DR-Ru catalysts in $0.5 \mathrm{~mol} \mathrm{~L}^{-1} \mathrm{H}_{2} \mathrm{SO}_{4}$ or $1 \mathrm{~mol} \mathrm{~L}^{-1} \mathrm{KOH}$ solution. (d) Comparison of the TOF values of DR-Ru catalysts with advanced noble metal electrocatalysts at $100 \mathrm{mV}$.

those for all previously reported Ru HER catalysts, such as Ru-GC $\left(0.9 \mathrm{~s}^{-1}\right)$ [34], Ru-Ni@Ni 2 -HNRs $\left(1.1 \mathrm{~s}^{-1}\right)$ [35], and $\mathrm{Ru} / \mathrm{g}-\mathrm{C}_{3} \mathrm{~N}_{4} / \mathrm{C}\left(4.9 \mathrm{~s}^{-1}\right)$ [26]. For most noble metal HER catalysts, the TOF in alkaline electrolyte is much lower than that in acidic electrolyte. For instance, the TOFs of Pt surface and Pt-based single-atom catalysts under alkaline conditions are approximately 1-2 orders of magnitude lower than those under acidic conditions [9,32]. As shown in Fig. 2d, DR-Ru catalysts also display a high TOF value of $\sim 16.4 \mathrm{~s}^{-1}$ in $1 \mathrm{~mol} \mathrm{~L}^{-1} \mathrm{KOH}$ at a $100-\mathrm{mV}$ overpotential, which is over 5 times larger than that of $\mathrm{Ru}\left(2.8 \mathrm{~s}^{-1}\right)$. DR-Ru outperforms the vast majority of the representative HER noble metal electrocatalysts reported recently, such as $\mathrm{Ru} / \mathrm{C}\left(2.0 \mathrm{~s}^{-1}\right), \mathrm{Ir} / \mathrm{C}\left(2.6 \mathrm{~s}^{-1}\right)$, $\mathrm{Ru} / \mathrm{g}-\mathrm{C}_{3} \mathrm{~N}_{4} / \mathrm{C}\left(4.2 \mathrm{~s}^{-1}\right)$ [26], PtAl $\left(5.6 \mathrm{~s}^{-1}\right)$ [33], Ru-HPC $\left(9.2 \mathrm{~s}^{-1}\right)$ [32], Ru@NC $\left(10.8 \mathrm{~s}^{-1}\right)$ [36] and PtGa $\left(17.1 \mathrm{~s}^{-1}\right)$ [33], at overpotentials of $100 \mathrm{mV}$. Our DR-Ru catalyst is also the only catalyst that exhibits a TOF of $>10 \mathrm{~s}^{-1}$ in both acidic and alkaline electrolytes.

The above HER results indicate that the abundant defects on the DR-Ru surface not only increase the number of surface catalytic sites, but also change the dynamic behavior so that the intrinsic activity of DR-Ru is equivalent in acidic and alkaline solutions. To further confirm this, the electrochemical surface areas of DR-Ru and $\mathrm{Ru}$ were investigated by the underpotential deposition of $\mathrm{Cu}$ (Fig. S6). There is an approximately 1.5 -fold difference between their superficial areas, which is much smaller than the 5-fold difference in TOF. To further verify that the activity comes from abundant defects, we conducted a second annealing of $\mathrm{DR}-\mathrm{Ru}$, which is beneficial to eliminating defects. As shown in Fig. S7, the $2^{\text {nd }}$ annealing DR-Ru NPs resulted in an average size of $\sim 2.6 \mathrm{~nm}$, slightly larger than that of DR-Ru. The resulting DR-Ru NPs displayed clear lattice fringes, implying that numerous defects were eliminated. The LSV curves (Fig. S8) further show that the overpotential increased significantly, even exceeding that of Ru.

To determine the underlying mechanism of the outstanding HER performance of DR-Ru catalysts, the chemical environment of the surface $\mathrm{Ru}$ was investigated by XPS spectra. As shown in Fig. 3a, both Ru-based catalysts 

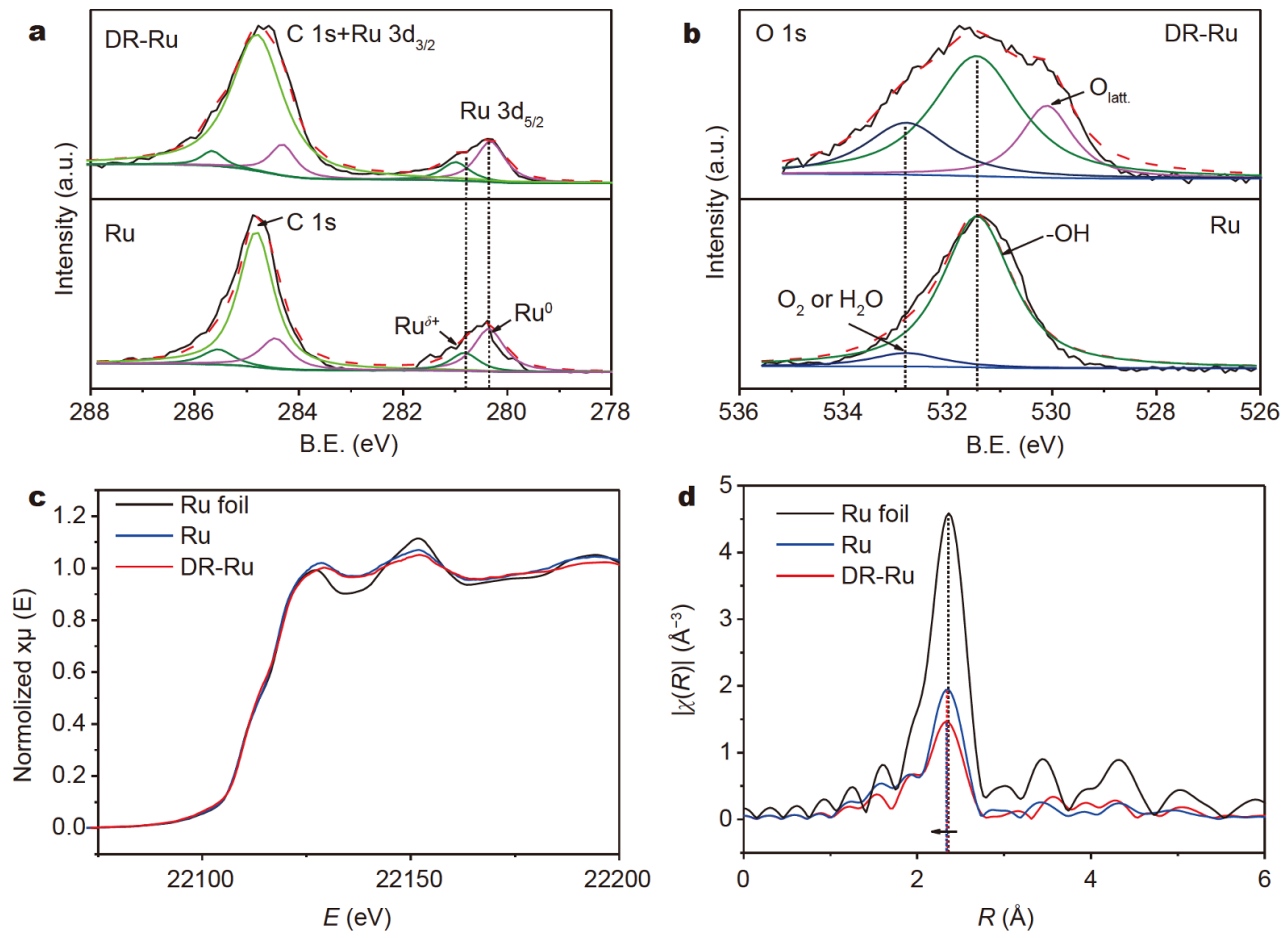

Figure 3 XPS spectra of Ru and DR-Ru. (a) Ru 3d and C 1s; (b) O 1s levels. (c) Ru K-edge XANES spectra for the as-prepared Ru, DR-Ru and reference Ru foil. (d) The magnitude of $k^{2}$-weighted Fourier transforms of the Ru K-edge EXAFS spectra for the as-prepared Ru, DR-Ru and reference $\mathrm{Ru}$ foil.

are mainly composed of metal $\mathrm{Ru}\left(\mathrm{Ru}^{0}\right)$ deposited with a binding energy (BE) of $\sim 280.3 \mathrm{eV}$, with only a small part of the oxidized $\mathrm{Ru}\left(\mathrm{Ru}^{\delta+}\right)$ displaying a higher BE [37]. The partial oxidation of surface metals is well known for metal nanomaterials exposed to the atmosphere. Interestingly, the peak position of the $\mathrm{Ru}^{\delta+}$ component in the $\mathrm{Ru} 3 \mathrm{~d}_{5 / 2}$ spectrum of DR-Ru obviously shifts to higher BE relative to that of Ru, implying that the surface Ru on DR-Ru NPs may possess a higher oxidation state. The $\mathrm{O} 1 \mathrm{~s}$ spectra of $\mathrm{DR}-\mathrm{Ru}$ in Fig. $3 \mathrm{~b}$ confirm the existence of $\mathrm{O}_{\text {latt. }}$ $(530.1 \mathrm{eV})$, and the other two contributions at 531.5 and $532.8 \mathrm{eV}$ can be ascribed to adsorbed oxygen species such as $\mathrm{OH}, \mathrm{H}_{2} \mathrm{O}$ or absorbed molecular $\mathrm{O}_{2}$ [38]. Compared with the $\mathrm{O}$ 1s spectra of $\mathrm{Ru}$, the appearance of $\mathrm{O}_{\text {latt. }}$ in $\mathrm{DR}-\mathrm{Ru}$ also indicates that the coordination environment around the $\mathrm{Ru}$ atom varies.

XANES and EXAFS experiments were conducted to further understand the local structure surrounding the surface defects of DR-Ru catalysts. Fig. 3c exhibits the normalized XANES spectra of Ru and DR-Ru NPs at the $\mathrm{Ru} \mathrm{K}$-edge with $\mathrm{Ru}$ foil as a reference. The Ru K-edge of the two Ru-based catalysts did not shift significantly relative to $\mathrm{Ru}$ foil, indicating that they maintain good metallicity. However, their white-line (WL) peak intensities increased slightly, which usually corresponds to the transition from $\mathrm{Ru} 1 \mathrm{~s}$ to $4 \mathrm{~d}$ and $\mathrm{d}-\mathrm{p}$ hybridized orbitals [39]. This phenomenon shows that the electronic structure of the outermost layer was changed. In addition, the $\mathrm{Ru}$ K-edge EXAFS $k^{2} \chi$ function (Fig. S9) displays an significantly reduced amplitude for DR-Ru compared with $\mathrm{Ru}$, implying a different local $\mathrm{Ru}$ atomic coordination environment. The corresponding Fourier transformed R-space spectra of DR-Ru in Fig. 3d present the predominant $\mathrm{Ru}-\mathrm{Ru}$ metallic coordination at $\sim 2.3 \AA$ and a slight shift to the lower $R$ values compared with that of $\mathrm{Ru}$ NPs and $\mathrm{Ru}$ foil. The shift in bonding length can be ascribed to the surface contraction in the nanostructure, consistent with previous TEM results [40,41]. However, the intensities of the $\mathrm{Ru}-\mathrm{Ru}$ coordination peaks of DR-Ru and $\mathrm{Ru}$ NPs present large decreases relative to those of $\mathrm{Ru}$ foil, especially after $\mathrm{Cu}$ etching, which indicates the appearance of defects (such as ruthenium vacancies). To quantitatively determine the local coordination environment of Ru-based catalysts, we fitted the Ru K-edge $k^{2}$-weighted EXAFS spectra for $\mathrm{Ru}$ and DR-Ru with $\mathrm{Ru}$ foil as a reference, and the results are shown in Fig. S10 and Table S1. The CN for surface Ru-Ru bonds in DR-Ru catalysts is 6.4 , which is significantly lower than that of 
Ru catalysts $(\mathrm{CN}=9)$, implying a difference in the surface $\mathrm{Ru}$ atom coordination environment. In theory, the $\mathrm{CN}$ of NPs with a size of $\sim 3.3 \mathrm{~nm}$ is approximately 10.6-10.8. In comparison, when the size of the NPs reaches $\sim 2.4 \mathrm{~nm}$, the $\mathrm{CN}$ is reduced to $10.0-10.4[42,43]$. In this case, the equivalent $\mathrm{CN}$ for $\mathrm{Ru}-\mathrm{Ru}$ bonds in $\mathrm{Ru}$ catalysts is approximately 10.8 , while that of $\mathrm{Ru}-\mathrm{Ru}$ bonds for $\mathrm{DR}-\mathrm{Ru}$ catalysts is only 9.2. The deviation of $\mathrm{CN}$ for DR-Ru means that DR-Ru has many surface Ru vacancies, which leads to abundant low coordination surface active sites with optimized electronic structure and potential activity for proton adsorption and desorption [36,44]. Above all, the enrichment of defects in the DR-Ru introduced lattice Os into the subsurface to adjust the electronic structure configurations and further lowered the $\mathrm{CN}$ of surface $\mathrm{Ru}$ to optimize the overall coordination environments of active $\mathrm{Ru}$ sites.

Operando SR-FTIR measurements, which have been proven to be effective in detecting OER and ORR intermediates at the solid-liquid interface [45-47], were first used to detect the dynamic evolution of the HER process. As shown in Fig. 4a, a new absorption band near $1100 \mathrm{~cm}^{-1}$ and a weak absorption signal at $834 \mathrm{~cm}^{-1}$ appear as the applied potential was increased from open circuit to $-30 \mathrm{mV} v$ s. RHE, which is generally ascribed to the $\mathrm{H}$ atoms adsorbed on threefold sites of the supported $\mathrm{Ru}$ particles [48]. This indicates that the HER process mainly involves the adsorption and reconstruction of protons under acidic conditions. Under alkaline conditions, however, the mechanism is much more complicated. At the onset potential ( $\sim 10 \mathrm{mV} v s$. RHE), a weak absorption peak located at $1634 \mathrm{~cm}^{-1}$ (marked by the green area in Fig. 4b) is observed, which is attributed to the bending mode of adsorbed water $\left(\mathrm{H}_{2} \mathrm{O}_{\mathrm{ad}}, \delta_{\mathrm{HOH}}\right)$, indicating that alkaline HER electrocatalysis is initiated by the adsorption of $\mathrm{H}_{2} \mathrm{O}$. With increasing applied potential, the strength of the peak for adsorbed $\mathrm{H}_{2} \mathrm{O}$ increases, and a new absorption signal with a potential-dependent relationship appears at $\sim 1840 \mathrm{~cm}^{-1}$. These variations in the spectra imply that the exposed sites of the DR-Ru surface are occupied by adsorbed $\mathrm{H}$ (abbreviated as $\mathrm{H}_{\text {ad }}$ ), which may come from the decomposition of $\mathrm{H}_{2} \mathrm{O}_{\text {ad }}$. Hence, the catalytic cycle in alkaline solution can be described as shown in Fig. 4c. $\mathrm{H}_{2} \mathrm{O}$ molecules are first adsorbed on the optimized active surface of DR-Ru and then dissociate into adsorbed $\mathrm{OH}$ and $\mathrm{H}_{\mathrm{ad}}$ (steps I-II), which are well known to be sluggish Volmer steps. Subsequently, the adsorbed $\mathrm{OH}$ breaks away from the DR-Ru active surface (step III). Then, the ready recombination reaction of $\mathrm{H}_{\mathrm{ad}}$ with an adjacent $\mathrm{H}_{2} \mathrm{O}$ in the solution (step IV) occurs and further releases $\mathrm{OH}^{-}$to generate $\mathrm{H}_{2}$ (step V). These reaction steps correspond to the fast Heyrovsky process, as previously analyzed.

First-principles density functional theory (DFT) calculations of the kinetics and thermodynamics of the HER were further performed to explore the origin of the high a
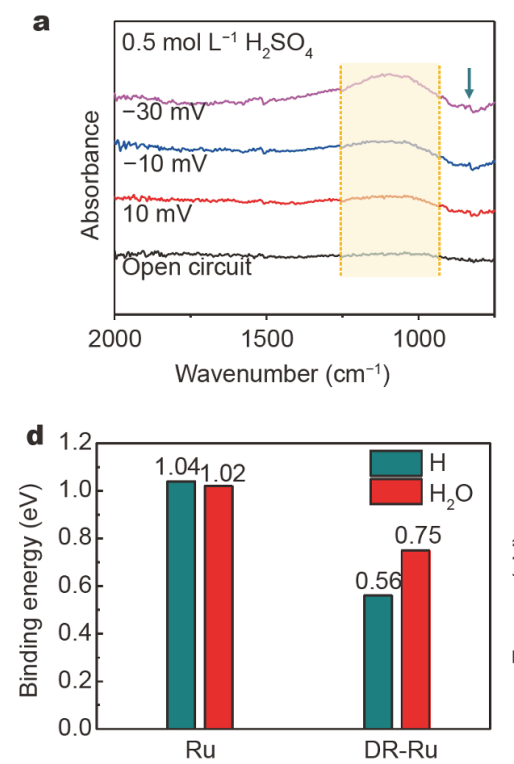

b

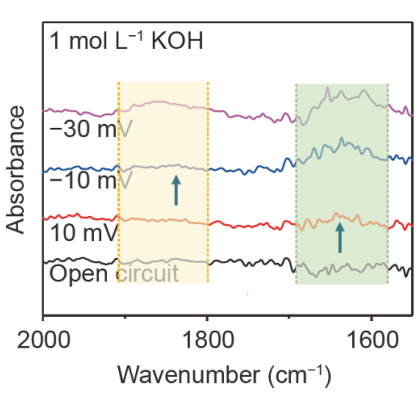

c

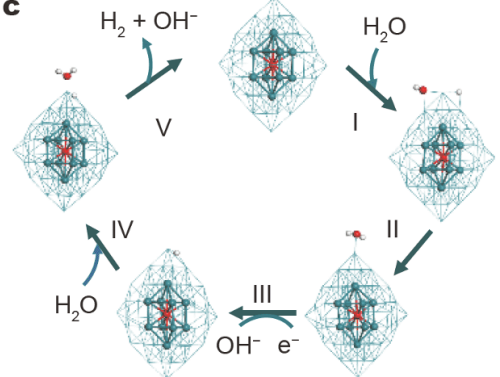

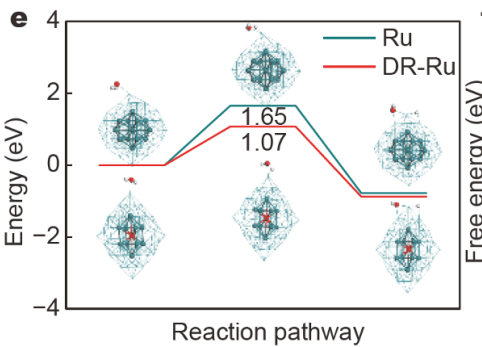

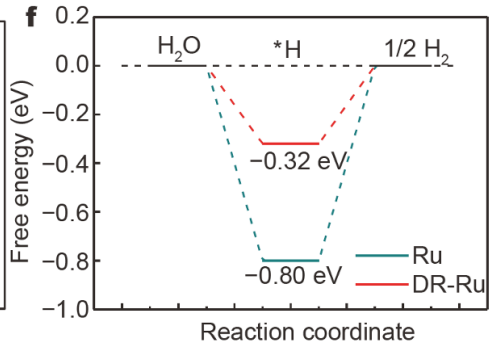

Figure 4 (a, b) Operando SR-FTIR measurements of DR-Ru in acidic and alkaline solutions, respectively. (c) HER mechanism for DR-Ru in alkaline solution. (d) The BEs of $\mathrm{H}_{\mathrm{ad}}$ and $\mathrm{H}_{2} \mathrm{O}_{\mathrm{ad}}$ on $\mathrm{Ru}$ and DR-Ru. (e) Calculated reaction barriers for $\mathrm{H}_{2} \mathrm{O}$ dissociation on Ru and DR-Ru. (f) Free energy diagram for the HER on Ru and DR-Ru NPs. 
electrocatalytic activity of DR-Ru in both acidic and alkaline solutions. A cubo-octahedron $\mathrm{Ru}_{55}$ model was optimized to represent the Ru NPs, and its central $\mathrm{Ru}$ atom was replaced by an oxygen atom to simulate the introduction of lattice oxygen in DR-Ru. In addition, the two marked $\mathrm{Ru}$ atoms in the subsurface layer of $\mathrm{Ru}_{55}$ were removed to show the lower CN of DR-Ru (Fig. S11). The $\mathrm{H}_{\mathrm{ad}}$ binding energies $\left(E_{\text {bin }}\right)$ on the DR-Ru and Ru NPs were first examined because it is generally believed that $\mathrm{Ru}$ is a theoretically suitable alternative to Pt because its hydrogen bond energy is similar to that of Pt-H [49]. However, fundamental studies on HER electrocatalysts in acidic environments suggested that $\mathrm{Ru}$-bound hydrogen is too strongly bound in acidic solutions, which is unfavorable for hydrogen evolution and leads to the relatively poor HER performance compared with Pt [50]. In our case, the $E_{\text {bin }}$ of $\mathrm{H}_{\mathrm{ad}}$ on DR-Ru is significantly decreased (to $\sim 0.56 \mathrm{eV}$ ) relative to that on $\mathrm{Ru}(\sim 1.04 \mathrm{eV}$ ), as shown in Fig. 4d; this is beneficial for the acceleration of the Tafel chemical recombination step $\left(2 \mathrm{H}_{\mathrm{ad}} \rightarrow \mathrm{H}_{2}\right)$ on $\mathrm{DR}-\mathrm{Ru}$, which is consistent with the experimental observations. In basic media, $\mathrm{H}_{2} \mathrm{O}$ is more easily adsorbed on the surface of Ru first, and the $E_{\text {bin }}$ of $\mathrm{H}_{2} \mathrm{O}_{\text {ad }}$ is stronger than that on DR-Ru, 1.02 vs. $0.75 \mathrm{eV}$. However, as shown in Fig. 2e, $\mathrm{Ru}$ has a large energy barrier for $\mathrm{H}_{2} \mathrm{O}$ dissociation $(1.65 \mathrm{eV})$, indicating extremely sluggish kinetics. In contrast, this energy barrier is significantly decreased to $1.07 \mathrm{eV}$ on DR-Ru and is also much lower than that on $\mathrm{Pt}(111)(2.64 \mathrm{eV})$ [51]. These results suggest that $\mathrm{Ru}$ can promote much faster $\mathrm{H}_{2} \mathrm{O}$ capture but cannot decompose $\mathrm{H}_{2} \mathrm{O}_{\mathrm{ad}}$ into $\mathrm{H}_{\mathrm{ad}}$ and $\mathrm{OH}_{\mathrm{ad}}$ quickly enough to afford sufficient protons for the HER process. For DR-Ru, a moderate $\mathrm{H}_{2} \mathrm{O}$ capture rate and the much easier dissociation of $\mathrm{H}_{2} \mathrm{O}$ are conducive to overcoming the delayed dynamics of the Volmer reaction in basic solution and further improve the equivalent reaction efficiency compared with that in acidic solution. In addition, the adsorption free energy of atomic hydrogen $\left(\Delta G_{\mathrm{Had}}\right)$ is a reliable descriptor for evaluating the HER activity of a given catalytic site, and the optimal value is generally recognized to be $\sim 0 \mathrm{eV}$ for an ideal HER electrocatalyst $[35,52]$. The free energy changes for Ru and DR-Ru NPs are shown in Fig. 4f. The $\Delta G_{\mathrm{Had}}$ of DR-Ru is $-0.32 \mathrm{eV}$, which is closer to the optimal $\Delta G_{\text {Had }}$ than that of Ru $(-0.80 \mathrm{eV})$, further demonstrating the more favorable reactivity of DR-Ru NPs during the HER process.

\section{CONCLUSIONS}

In summary, a defect-enriched $h c p$-Ru electrocatalyst with a $\sim 2.4 \mathrm{~nm}$ particle size was synthesized successfully via a novel two-step approach. As a promising acid HER electrocatalyst, DR-Ru rapidly realized a current density of $10 \mathrm{~mA} \mathrm{~cm}^{-2}$ with a low overpotential of $25.1 \mathrm{mV}$ and displayed an excellent TOF value of $20.6 \mathrm{~s}^{-1}$ at an overpotential of $100 \mathrm{mV}$. A comparable HER performance with an overpotential of $28.2 \mathrm{mV}$ at $10 \mathrm{~mA} \mathrm{~cm}^{-2}$, ultrahigh TOF of $16.4 \mathrm{~s}^{-1}$ at $100 \mathrm{mV}$ overpotential and continuous $20 \mathrm{~h}$ long-term durability was also realized in alkaline solution. Both experimental and theoretical analyses disclosed that the rich defects of DR-Ru are the key to boosting the enhanced HER performance. Especially under alkaline conditions, adjusting the electronic structure and coordination environment of active $\mathrm{Ru}$ sites caused DR-Ru to exhibit a much more moderate $\mathrm{H} / \mathrm{H}_{2} \mathrm{O}$ binding energy and excellent dissociation energy for $\mathrm{H}_{2} \mathrm{O}$, which results in the more efficient alkaline HER compared with that of Ru. This discovery provides new insights into improving the high mass-specific reactivity of noble metal catalysts in various harsh electrolytes and offers a feasible strategy for the rational design of the active site structures of electrocatalysts.

Received 22 December 2020; accepted 26 February 2021; published online 29 April 2021

1 Tiwari JN, Sultan S, Myung CW, et al. Multicomponent electrocatalyst with ultralow Pt loading and high hydrogen evolution activity. Nat Energy, 2018, 3: 773-782

2 Mahmood J, Li F, Jung SM, et al. An efficient and pH-universal ruthenium-based catalyst for the hydrogen evolution reaction. Nat Nanotech, 2017, 12: 441-446

3 Li C, Baek JB. Recent advances in noble metal ( $\mathrm{Pt}, \mathrm{Ru}$, and $\mathrm{Ir}$ )based electrocatalysts for efficient hydrogen evolution reaction. ACS Omega, 2020, 5: 31-40

4 Gannon WJF, Dunnill CW. Raney nickel 2.0: Development of a high-performance bifunctional electrocatalyst. Electrochim Acta, 2019, 322: 134687

5 Zhang J, Wang T, Liu P, et al. Efficient hydrogen production on $\mathrm{MoNi}_{4}$ electrocatalysts with fast water dissociation kinetics. Nat Commun, 2017, 8: 15437-15444

6 Jasiński D, Meredith J, Kirwan K. The life cycle impact for platinum group metals and lithium to 2070 via surplus cost potential. Int J Life Cycle Assess, 2018, 23: 773-786

7 Sverdrup HU, Ragnarsdottir KV. A system dynamics model for platinum group metal supply, market price, depletion of extractable amounts, ore grade, recycling and stocks-in-use. Resour Conserv Recycl, 2016, 114: 130-152

8 Qiao B, Wang A, Yang X, et al. Single-atom catalysis of Co oxidation using $\mathrm{Pt}_{1} / \mathrm{FeO}_{x}$. Nat Chem, 2011, 3: 634-641

9 Fang S, Zhu X, Liu X, et al. Uncovering near-free platinum singleatom dynamics during electrochemical hydrogen evolution reaction. Nat Commun, 2020, 11: 1029-1035

10 Liu D, Li X, Chen S, et al. Atomically dispersed platinum supported on curved carbon supports for efficient electrocatalytic hydrogen evolution. Nat Energy, 2019, 4: 512-518

11 Fu Q, Li WX, Yao Y, et al. Interface-confined ferrous centers for 
catalytic oxidation. Science, 2010, 328: 1141-1144

12 Fang Z, Dürholt JP, Kauer M, et al. Structural complexity in metalorganic frameworks: Simultaneous modification of open metal sites and hierarchical porosity by systematic doping with defective linkers. J Am Chem Soc, 2014, 136: 9627-9636

13 Fang Z, Bueken B, De Vos DE, et al. Defect-engineered metalorganic frameworks. Angew Chem Int Ed, 2015, 54: 7234-7254

$14 \mathrm{Lu} \mathrm{K}, \mathrm{Lu} \mathrm{L}$, Suresh S. Strengthening materials by engineering coherent internal boundaries at the nanoscale. Science, 2009, 324: 349-352

15 Anderson CP, Bourassa A, Miao KC, et al. Electrical and optical control of single spins integrated in scalable semiconductor devices. Science, 2019, 366: 1225-1230

$16 \mathrm{Hu} \mathrm{L}$, Zhu T, Liu X, et al. Point defect engineering of highperformance bismuth-telluride-based thermoelectric materials. Adv Funct Mater, 2014, 24: 5211-5218

17 Chen D, Guan Z, Zhang D, et al. Constructing a pathway for mixed ion and electron transfer reactions for $\mathrm{O}_{2}$ incorporation in $\mathrm{Pr}_{0.1} \mathrm{Ce}_{0.9} \mathrm{O}_{2-\mathrm{x}}$. Nat Catal, 2020, 3: 116-124

18 Lv C, Qian Y, Yan C, et al. Defect engineering metal-free polymeric carbon nitride electrocatalyst for effective nitrogen fixation under ambient conditions. Angew Chem Int Ed, 2018, 57: 10246-10250

19 Yan D, Li Y, Huo J, et al. Defect chemistry of nonprecious-metal electrocatalysts for oxygen reactions. Adv Mater, 2017, 29: 1606459

20 Zhao Y, Chang C, Teng F, et al. Defect-engineered ultrathin $\delta$ $\mathrm{MnO}_{2}$ nanosheet arrays as bifunctional electrodes for efficient overall water splitting. Adv Energy Mater, 2017, 7: 1700005

21 Jiang $\mathrm{H}, \mathrm{Gu}$ J, Zheng X, et al. Defect-rich and ultrathin $\mathrm{N}$ doped carbon nanosheets as advanced trifunctional metal-free electrocatalysts for the ORR, OER and HER. Energy Environ Sci, 2019, 12: $322-333$

22 Xie J, Zhang H, Li S, et al. Defect-rich $\mathrm{MoS}_{2}$ ultrathin nanosheets with additional active edge sites for enhanced electrocatalytic hydrogen evolution. Adv Mater, 2013, 25: 5807-5813

23 Ozden S, Bawari S, Vinod S, et al. Interface and defect engineering of hybrid nanostructures toward an efficient HER catalyst. Nanoscale, 2019, 11: 12489-12496

24 Ling Y, Yang Z, Zhang Q, et al. A self-template synthesis of defectrich $\mathrm{WS}_{2}$ as a highly efficient electrocatalyst for the hydrogen evolution reaction. Chem Commun, 2018, 54: 2631-2634

25 Ye G, Gong Y, Lin J, et al. Defects engineered monolayer $\mathrm{MoS}_{2}$ for improved hydrogen evolution reaction. Nano Lett, 2016, 16: 10971103

26 Zheng Y, Jiao Y, Zhu Y, et al. High electrocatalytic hydrogen evolution activity of an anomalous ruthenium catalyst. J Am Chem Soc, 2016, 138: 16174-16181

27 Li Y, Zhou W, Zhao X, et al. Donutlike RuCu nanoalloy with ultrahigh mass activity for efficient and robust oxygen evolution in acid solution. ACS Appl Energy Mater, 2019, 2: 7483-7489

28 Okamoto H. Cu-Ru (copper-ruthenium). J Phase Equilib, 1992, 13: 440

29 Jongsomjit B, Panpranot J, Goodwin Jr. JG. Co-support compound formation in alumina-supported cobalt catalysts. J Catal, 2001, 204: 98-109

30 Miao X, Zhang L, Wu L, et al. Quadruple perovskite ruthenate as a highly efficient catalyst for acidic water oxidation. Nat Commun, 2019, 10: 3809-3815

31 Mahmood N, Yao Y, Zhang JW, et al. Electrocatalysts for hydrogen evolution in alkaline electrolytes: Mechanisms, challenges, and prospective solutions. Adv Sci, 2018, 5: 1700464
32 Durst J, Siebel A, Simon C, et al. New insights into the electrochemical hydrogen oxidation and evolution reaction mechanism. Energy Environ Sci, 2014, 7: 2255-2260

33 Vuković M, Čukman D. Electrochemical quartz crystal microbalance study of electrodeposited ruthenium. J Electroanal Chem, 1999, 474: 167-173

34 Drouet $\mathrm{S}$, Creus J, Collière V, et al. A porous Ru nanomaterial as an efficient electrocatalyst for the hydrogen evolution reaction under acidic and neutral conditions. Chem Commun, 2017, 53: 11713-11716

35 Liu Y, Liu S, Wang Y, et al. Ru modulation effects in the synthesis of unique rod-like $\mathrm{Ni@Ni} 2 \mathrm{P}-\mathrm{Ru}$ heterostructures and their remarkable electrocatalytic hydrogen evolution performance. J Am Chem Soc, 2018, 140: 2731-2734

36 Cheng W, Zhang H, Zhao X, et al. A metal-vacancy-solid-solution NiAlP nanowall array bifunctional electrocatalyst for exceptional all-pH overall water splitting. J Mater Chem A, 2018, 6: 9420-9427

37 Shen JY, Adnot A, Kaliaguine S. An ESCA study of the interaction of oxygen with the surface of ruthenium. Appl Surf Sci, 1991, 51: $47-60$

38 Hou Y, Li J, Wen $\mathrm{Z}$, et al. $\mathrm{Co}_{3} \mathrm{O}_{4}$ nanoparticles embedded in nitrogen-doped porous carbon dodecahedrons with enhanced electrochemical properties for lithium storage and water splitting. Nano Energy, 2015, 12: 1-8

39 Zhou Y, Xie Z, Jiang J, et al. Lattice-confined Ru clusters with high $\mathrm{CO}$ tolerance and activity for the hydrogen oxidation reaction. Nat Catal, 2020, 3: 454-462

40 Miller JT, Kropf AJ, Zha Y, et al. The effect of gold particle size on $\mathrm{AuAu}$ bond length and reactivity toward oxygen in supported catalysts. J Catal, 2006, 240: 222-234

41 Lei Y, Jelic J, Nitsche LC, et al. Effect of particle size and adsorbates on the $\mathrm{L}_{3}, \mathrm{~L}_{2}$ and $\mathrm{L}_{1} \mathrm{X}$-ray absorption near edge structure of supported Pt nanoparticles. Top Catal, 2011, 54: 334-348

42 Marinkovic NS, Sasaki K, Adzic RR. Nanoparticle size evaluation of catalysts by EXAFS: Advantages and limitations. Zas Mat, 2016, 57: 101-109

43 Mirjalili M, Vahdati-Khaki J. Prediction of nanoparticles' sizedependent melting temperature using mean coordination number concept. J Phys Chem Solids, 2008, 69: 2116-2123

44 Tang F, Cheng W, Su H, et al. Smoothing surface trapping states in 3D coral-like $\mathrm{CoOOH}$-wrapped- $\mathrm{BiVO}_{4}$ for efficient photoelectrochemical water oxidation. ACS Appl Mater Interfaces, 2018, 10: 6228-6234

45 Su H, Zhou W, Zhang H, et al. Dynamic evolution of solid-liquid electrochemical interfaces over single-atom active sites. J Am Chem Soc, 2020, 142: 12306-12313

46 Cheng W, Zhao X, Su H, et al. Lattice-strained metal-organicframework arrays for bifunctional oxygen electrocatalysis. Nat Energy, 2019, 4: 115-122

47 Zhao X, Su H, Cheng W, et al. Operando insight into the oxygen evolution kinetics on the metal-free carbon-based electrocatalyst in an acidic solution. ACS Appl Mater Interfaces, 2019, 11: 3485434861

48 Izumi Y, Hoshikawa M, Aika K. Adsorbed hydrogen effect on the adsorption and reactivity of $\mathrm{N}_{2}$ molecules on $\mathrm{Ru} / \mathrm{MgO}$ and $\mathrm{Ru}-$ $\mathrm{Cs}^{+} / \mathrm{MgO}$ : Hydrogen dipole effect enhanced by doped $\mathrm{Cs}^{+}$. Bull Chem Soc Jpn, 1994, 67: 3191-3200

49 Zhang J, Xu X, Yang L, et al. Single-atom Ru doping induced phase transition of $\mathrm{MoS}_{2}$ and S vacancy for hydrogen evolution reaction. Small Methods, 2019, 3: 1900653 
50 Jiao Y, Zheng Y, Jaroniec M, et al. Design of electrocatalysts for oxygen- and hydrogen-involving energy conversion reactions. Chem Soc Rev, 2015, 44: 2060-2086

51 Liu J, Ding G, Yu J, et al. Visualizing spatial potential and charge distribution in $\mathrm{Ru} / \mathrm{N}$-doped carbon electrocatalysts for superior hydrogen evolution reaction. J Mater Chem A, 2019, 7: 1807218080

52 Hinnemann B, Moses PG, Bonde J, et al. Biomimetic hydrogen evolution: $\mathrm{MoS}_{2}$ nanoparticles as catalyst for hydrogen evolution. J Am Chem Soc, 2005, 127: 5308-5309

Acknowledgements This work was supported by the National Natural Science Foundation of China (U1932212, 11875257, and U1932109), and the Fundamental Research Funds for the Central Universities (WK2310000070).

Author contributions Li Y designed and engineered the samples; Cheng $\mathrm{W}$ conceived the post-fabrication tuning of random modes; Li Y performed the experiments; Zhang H, Liu M and Zhou W performed the data analysis; Li Y wrote the paper with support from $\mathrm{He} \mathrm{J,} \mathrm{Li} \mathrm{C} \mathrm{and}$ Liu Q; Chen X contributed to the theoretical analysis. All authors contributed to the general discussion.

Conflict of interest The authors declare that they have no conflict of interest.

Supplementary information Experimental details and supporting data are available in the online version of the paper.

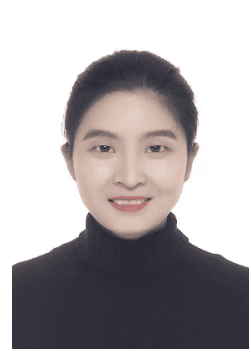

Yuanli Li is currently a $\mathrm{PhD}$ candidate in the National Synchrotron Radiation Laboratory, University of Science and Technology of China (USTC) under the supervision of Prof. Shiqiang Wei and Prof. Qinghua Liu. She received her ME degree in 2011 from Sichuan University. She joined Southwest University of Science and Technology as an assistant professor in 2013. Her current research interests focus on (photo)electrochemistry of energy conversion nanomaterials and advanced in situ/operando synchrotron radiation experimental techniques.

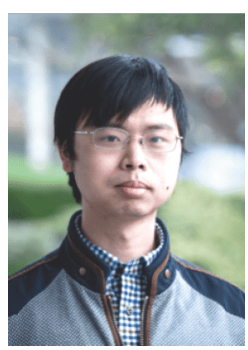

Jingfu He is currently an associate professor at the School of Materials, Sun Yat-sen University. $\mathrm{He}$ received his $\mathrm{PhD}$ degree in 2012 from USTC. He joined Berlinguette group at the University of British Columbia as a postdoctoral associate in 2015 and conducted research on $\mathrm{CO}_{2}$ electrocatalysts and electrolyzer. His current research interests include photoelectrochemistry and electrochemistry for solar energy conversion.

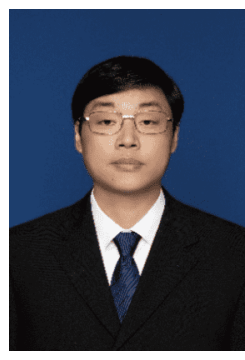

Xin Chen is currently an associate professor at the College of Chemistry and Chemical Engineering, Southwest Petroleum University. He received his $\mathrm{PhD}$ degree in 2014 from Beijing University of Technology. From December 2014 to December 2016, he was a postdoctoral fellow supervised by Prof. Dingguo Xia at Peking University. His current research interest is focused on the electrocatalysis of fuel cells and heterogeneous catalysis with first principles calculations.

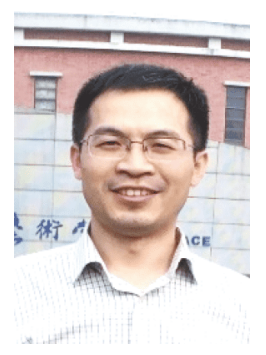

Qinghua Liu is currently a member of the $\mathrm{Na}$ tional Synchrotron Radiation Laboratory, USTC. He received his $\mathrm{PhD}$ degree in 2009 from USTC. His current research interests focus on the synthesis and characterizations of advanced energy functional nanomaterials for photocatalytic, electrochemical, and photoelectrochemical applications and the development of advanced in situ/operando synchrotron radiation experimental techniques and their applications in energy storage and reaction mechanism.

\section{缺陷富集型钉基电催化剂在强碱和强酸析氢反应 中的高质量比活性研究}

李园利 ${ }^{1,2}$, 何劲 夫 $^{3^{*}}$, 程位任 ${ }^{1}$, 苏徽 ${ }^{1}$, 李昌黎 ${ }^{3}$, 张慧 ${ }^{1}$, 刘美欢 ${ }^{1}$, 周婉琳 ${ }^{1}$, 陈金年茥, 刘庆华 ${ }^{1 *}$

摘要 合理的设计策略以提高贵金属电催化剂在析氢反应(HER) 中的利用率, 对于简化HER的工艺流程, 促进未来能源循环经济的 发展至关重要. 本文在约 $2.4 \mathrm{~nm}$ 的 Ru纳米颗粒上设计了大量的缺 陷, 使其在苛刻的酸性和碱性电解质中具有超高质量比反应活性. 在过电势为 $100 \mathrm{mV}$ 时, 所制备的缺陷富集型 $\mathrm{Ru}$ 基电催化剂 $\mathrm{DR}-\mathrm{Ru}$ 表现出超高的HER翻转频率(碱性: $16.4 \mathrm{~s}^{-1}$; 酸性: $20.6 \mathrm{~s}^{-1}$ ) 和超低 的过电势(碱性: $\eta_{10}=28.2 \mathrm{mV}$; 酸性: $\eta_{10}=25.1 \mathrm{mV}$ ), 明显优于其他 $\mathrm{Ru}$ 基电催化剂. 此外, 低配位的 $\mathrm{Ru}$ 活性位和表面部分晶格氧削弱了 $\mathrm{DR}-\mathrm{Ru}$ 的 $\mathrm{Ru}-\mathrm{H}$ 结合能, 促进了酸性HER进行; 同时有利于 $\mathrm{H}_{2} \mathrm{O}$ 分子 分解, 缓解了碱性HER过程中水分子的解离迟滞, 导致其具有与酸 性HER相当的高质量比活性. 